\title{
Epigenetics, brain, behavior, and the environment
}

\author{
David Crews
}

Ashbel Smith Professor of Zoology and Psychology, Section of Integrative Biology, University of Texas at Austin, U.S.A.

\begin{abstract}
Early experiences can modify regulatory factors affecting gene expression in such a way that, although the DNA sequence itself is not changed, the individual's physiology and behavior is substantially influenced. In some instances these epigenetic effects are exerted upon exposure, while in other instances they are transmitted across generations via incorporation into the germline. Examples of both types of epigenetic effects are presented. First, experience with siblings (littermates) organizes behaviors and their underlying neural substrates in such a way that, as adults, rats and knockout mice behave differently. Second, exposure to the fungicide vinclozolin early in pregnancy imprints the male lineage in such a manner that rats exhibit distinct behavioral profiles as well as unique patterns of gene expression in relevant brain regions. Taken together, this work demonstrates that present and past environments alike modify both social and affiliative related behaviors and their related metabolic activity in specific brain nuclei as well as influencing the abundance of specific genes altering the epigenome in the target brain areas.
\end{abstract}

Key words: Behavior, Environmental influences, Epigenetics

\section{INTRODUCTION}

Many psychiatric disorders exhibit significant gender differences in relative risk level and severity. In women, the incidence of some disorders (e.g. eating disorders, major depressive disorder, obsessive-compulsive disorder, posttraumatic stress disorders, anxiety and panic disorders, seasonal affective disorder, and Alzheimer's disease and dementia) is two-fold

\footnotetext{
Address for correspondence:

David Crews, Ashbel Smith Professor of Zoology and Psychology, Section of Integrative Biology, University of Texas at Austin, Austin, Texas 78712, Tel.: 512-471-1804 (direct), 512-471-1113 or 475-6738, e-mail: crews@mail.utexas.edu, Tel.: 512-471-6078 (direct), 512-471-3878 (department), Website: http://www.utexas.edu/research/crewslab Received 21-09-09, Revised 15-11-09, Accepted 18-12-09
}

higher or more than in men. Males are at higher risk for early onset disorders such as autism and schizophrenia. It is clear that in some manner reproductive and adrenal hormones play a role in the development and display of these disorders since, in many instances, the sex differences manifest at puberty. In some cases the relationship is clear-cut, as is the case with stress hormones and anxiety-related behaviors. However, a direct causative (vs. consequential) nature of sex steroid hormones has been more difficult to demonstrate even though, for example, in the case of schizophrenia in women, worsening of symptoms is experienced during pregnancy, postpartum, and perimenopause. ${ }^{1-3} \mathrm{~A}$ clearer picture emerges when we consider individuals exposed to exogenous steroids or their mimics. It is well known that conditions such as congenital adrenal 
hyperplasia, resulting in elevated androgen levels, influence subsequent gender identity and role. ${ }^{4,5}$ Even modestly higher in utero androgen exposure during fetal life has detectable effects in later adulthood. For example, a female dizygotic twin with a twin brother, as compared with a female dizygotic twin with a twin sister, exhibits more risk-taking behavior, has a more masculine pattern of cerebral lateralization, and is prone to aggression. ${ }^{6-8}$ Both men and women exposed to diethylstilbestrol (DES) in utero (hence having a body burden of the chemical) are more prone to depression compared to their unexposed siblings. ${ }^{9-11}$ Indeed, an issue of national concern is the significant environmental exposure to common-use chemicals in the household, a factor suggested as contributing to the increased incidence of affective disorders in the general population. ${ }^{12}$

When and how are these gender biases established? Hormones and genotype determine an individual's responses to experiences throughout the life cycle as well as the susceptibility to developing disorders. ${ }^{13-}$ ${ }^{15}$ Embryonic development is the time of maximal neuronal and behavioral plasticity, although the individual's capacity to respond to environmental change or insult with heritable phenotypic variation at a later stage is also possible. For the purposes of this essay, plasticity is defined as the ability of the genotype to produce different phenotypes in response to different environments. In both instances, suites of genes underlie the fundamental plasticity of an organism, particularly during development or life history transitions. Exploration of such gene-environment interactions furthers our understanding of how the environment influences the relationship between genotype and behavior during sensitive developmental periods.

Affective disorders result from the interplay of environmental, genetic, and epigenetic factors during neural development, but exactly how this comes about is relatively unknown. ${ }^{16,17}$ Recent studies at both the molecular and organismal levels indicate that the origin of such effects may be in previous generations. That is, experiences of earlier generations modify regulatory factors affecting gene expression in such a way that the DNA sequence itself is not changed but the individual's physiology and behavior are substantially influenced. Of particular interest is how such effects might be transmitted across generations. First, it is important to distinguish mitotic (non-germline) from meiotic (germline) epigenetic imprints.

\section{CONTEXT-DEPENDENT VS. GERMLINE- DEPENDENT EPIGENETIC MODIFICATIONS}

Transgenerational effects can be observed if the environmental factors that bring about the epigenetic modification simply continue to persist. ${ }^{18,19}$ For example, if the diet, behavior (see below), or environmental toxicant (e.g. lead) continues to be present in the environment, then epigenetic modification will be manifested in each generation. ${ }^{20,21}$ This situation leads to readily available therapeutic venues such as those providing methyl donors to the diet or directly to the young, or simply removing the environmental toxicant. ${ }^{22-24}$ Hence, the environment can induce epialleles, but this environmentally induced epigenetic state can be reversed by a different environmental factor. I term this mitotically based transgenerational effect 'Context-Dependent' epigenetic change and the best example comes from the work of Meaney and colleagues. ${ }^{18,23,25,26}$ In a long series of elegant studies, this group has demonstrated that nature and the amount of care a pup receives from the mother modulates its reaction to stress later in life largely through effects on the glucocorticoid receptor (GR) in the hippocampus. This maternal effect can cross generations, provided that the pup's experience occurs in the first week of life. Recently, this group has documented that infusion of methionine, a histone deacetylase inhibitor, into the hippocampus can also reverse these events. Is there a counterpart in humans? Caspi and colleagues have demonstrated how the rearing environment can overcome the influence of genotype in the etiology of violent behavior. ${ }^{27,28}$

Germline-Dependent epigenetic modification is fundamentally different than Context-Dependent epigenetic modification. ${ }^{18}$ This type of transgenerational epigenetic imprint is mediated through the germline and tends to be sex-linked. That is, an epigenetic modification is transferred to subsequent generations because the change in the epigenome is incorporated into the germline. Thus, the effect is manifested in each generation in the absence of the causative agent. In such instances the DNA methylation of heritable 
epialleles is passed through to subsequent generations rather than being erased as occurs normally during gametogenesis and shortly after fertilization. It should be emphasized that Germline-Dependent epigenetic modifications are not equivalent to genomic imprinting in which genes are monoallelically expressed in a parent-of-origin dependent manner. ${ }^{29,30}$ In the latter case of genomic imprinting, subsets of genes are silenced and influence development; silencing of genes is erased and not transmitted to the next generation. To date, there is but a single example of GermlineDependent epigenetic modification on behavior.

\section{EPIGENETICS AND MENTAL HEALTH}

A growing body of information suggests that epigenetic effects might extend to gender differences in brain and behavior. ${ }^{18,31}$ For example, Woolf and Grossman and colleagues have presented, compelling arguments that for certain psychopathological conditions (schizophrenia, fragile X syndrome, fetal alcohol syndrome, and depression), early developmental events canalize the individual into an evernarrowing range of responses..$^{32,33}$ It is significant that methylation has been implicated in the etiology of all of these disorders.

More than 70 years of research with animal models has demonstrated that gonadal and adrenal hormones organize the brain perinatally in such a way that the individual's perception, behavior, and learning abilities are modified. Not only does the nature and amount of hormone affect individual development but also the timing of hormone exposure is important. However, while the principle of critical periods of hormone sensitivity is well established in animal studies, the data on human behavior is only now being collected. ${ }^{34}$ Perhaps the best studied phenomenon is that of stress and how, if it is sustained, it can lead to impaired immunity, disease, and neurological changes characteristic of major depressive illness and particularly chronic anxiety disorders. ${ }^{35-37}$ Chronic restraint stress in rats has been a standard paradigm for studying such effects on physiology, brain, and behavior. For example, six hours daily of immobilization restraint for three weeks results initially in elevated corticosterone levels but after 21 days, the hypothalamus-pituitary-adrenal (HPA) axis shows ad- aptation and levels are back to normal. However, there is a progressive atrophy of the dendrite length and branching of pyramidal neurons in the CA3 region, a process mediated by corticosterone potentiating the release and postsynaptic activity of excitatory amino acids from adjacent mossy fiber terminals arising from the granule neurons in the dentate gyrus and acting via N-Methyl-D-Aspartate (NMDA) receptors. ${ }^{38}$ Conversely, there is an increase in dendritic spine density of neurons in the basolateral amygdala and Medial Prefrontal Cortex (mPFC), and decreased neurogenesis in the dentate gyrus. ${ }^{39-43}$ In addition to suppressing proliferation of new cells, chronic restraint markedly increases polysialic acid, a developmentally regulated carbohydrate associated with Neural Cell Adhesion Molecule (NCAM).${ }^{44}$ Stressed rats also exhibit a variety of specific cognitive deficits in spatial learning and memory as well as increased anxiety-like and agonistic behavior. ${ }^{39,45,46}$

The effects of stress appear to vary depending upon the sex of the individual and when they occur. ${ }^{47}$ For the purposes of this essay, I will only consider the literature on males. In males, the effects of chronic stress early in development tend to be irreversible, resulting in permanent structural changes in the hippocampus and altered adult sociosexual and anxiety-related behaviors, while those experienced as an adult can be reversed. If the stress occurs during the peripubertal-juvenile transition, the effects are similar to the early effects, if not exaggerated.$^{48}$ In rats, chronic restraint influences serotonin and dopamine activity in CA3 of the hippocampus, dopamine and its metabolites in CA1 of the hippocampus as well as the mPFC, and dopamine and its metabolites in the basolateral amygdala.

The context in which the stress is experienced is also important, perhaps not surprisingly as rats and humans are social animals. For example, stress decreases neurogenesis in the dentate gyrus of male rats that are individually housed but not in those that are socially housed. ${ }^{49}$ In humans, some disorders are precipitated by stress, which itself alters endocrine state. For example, only some of the pregnant women exposed directly to the World Trade Center collapse developed Posttraumatic Stress Disorder (PTSD). ${ }^{50}$ These women and their babies had lower cortisol levels compared with those mothers who did not develop 
PTSD. The issue here is whether stress potentiates a predisposition to develop mental disorder(s). A similar point has been raised by Petronis and colleagues regarding pre- and perinatal environmental risks for Attention-Deficit Hyperactivity Disorder (ADHD). ${ }^{5,51}$

It is now well accepted that life history events interact with genetic predispositions to induce disease. For example, Eker rats carry a germ line defect in the tuberous sclerosis complex 2 tumor-suppressor gene and approximately $65 \%$ develop hormone-dependent uterine leiomyomas..$^{52}$ Exposure of females to DES on days 3-5 after birth increases the tumor-suppressor-gene penetrance to more than $90 \%$. In principle, stress, which has been shown to have organizational actions of behavior in rats via an effect on the HPA, could have a similar potentiating effect on epigenetically induced transgenerational imprints as well as on genetic predisposition to develop disease. Indeed, glucocorticoid receptor regulates DNA methylation within a key enhancer of the rat liver-specific tyrosine aminotransferase gene, resulting in rapid chromatin remodeling. This demethylated state is stable and results in an enhanced hormonal response to glucocorticoids on additional exposure. ${ }^{53}$ An intriguing recent finding concerns differences in D2 Dopamine Receptor (DRD2) variants in PTSD patients that are co-morbid for anxiety, social dysfunction, and depression; methylation plays a role in DRD2 expression. ${ }^{54-58}$

Finally, perhaps the best evidence for epigenetic influences in affective disorders comes from studies of Monozygotic (MZ) twins. ${ }^{2,59}$ In such instances, the concordance rate for both of the twins to suffer from an affective disorder is higher than that observed in dizygotic twins or sib pairs (e.g. schizophrenia-70\% and autism-60\%). The fact that it is not complete is of interest but outside the scope of this brief review. Epigenetic MZ twin differences have been identified that vary with age, but also between twin pairs..$^{60,61}$ For example, the Catechol-O-Methyltransferase (COMT) gene is located on chromosome 22q11, a region implicated in the etiology of schizophrenia. ${ }^{62}$ Mill et al. studied the concordance rate for $\mathrm{CpG}$ methylation in the promoter region of this gene in 12 5 -year-old MZ twin pairs discordant for birth weight, finding a range of concordance from $<1$ to $42 \% .{ }^{63}$
More relevant to this discussion, a comparison of two MZ twin pairs, one concordant for the diagnosis of schizophrenia and the other discordant, revealed larger epigenetic difference in the regulatory region of the DRD2 gene. ${ }^{56}$

\section{NEURAL MECHANISMS UNDERLYING SOCIOSEXUAL AND EMOTIONAL BEHAVIORS}

There is now a substantial body of literature indicating that in mammals, specific nuclei in the limbic and forebrain areas are critical to the display of reproductive, agonistic, and emotional behaviors. ${ }^{64-71}$ These nuclei, which include the lateral septum, amygdala, hippocampus, bed nucleus of the stria terminalis, medial preoptic area, anterior hypothalamus, and ventral tegmental area, are interconnected, contain steroid hormone receptors, and tend to be sexually dimorphic in their volume and synaptic organization as a consequence of the nature and frequency of sex steroid hormones secreted perinatally. Ablation of individual nuclei often leads to diminution or even abolition of social and reproductive behaviors, whereas stimulation in individuals gonadectomized in adulthood restores these behaviors. Stress influences cognition and anxiety, effects that are sexually dimorphic and hormonally modulated. Moreover, the functional neuroendocrinology of brain areas associated with stress have been delineated (see above and below). The display of these complex behaviors is reflected in increased expression of immediate early genes as well as electrophysiological and metabolic activity in multiple nuclei that can form an integrated neuronal circuit. This has led to increased appreciation that social and reproductive behaviors "emerge from the activity of a unitary neuroanatomical framework" in the brain..$^{72}$ The Crews lab has been at the forefront of developing analytic methods for evaluating change in such networks. ${ }^{73}$

\section{CONTEXT-DEPENDENT EPIGENETIC CHANGES IN BRAIN AND BEHAVIOR}

Life history is continuous but can be viewed as the cumulation of discrete segments; each period emerges from what goes before and, at the same time, sets the stage for what follows. Although the divisions are somewhat arbitrary and some traits can 
span conventional divisions, in mammals the usual classification is prenatal (intrauterine), postnatal (until weaning), adolescence (after weaning), peripubertal, sexual maturity, and reproductive senescence. Each period has its own characteristic ethologies and particular contribution to the behavioral phenotype. It is possible to deconstruct early life events and study each period both in its own right and how it interacts with the other stages.

In the field of behavioral neuroscience, complex behavioral traits are typically studied in the adult organism. In mammals, the formative environment for social and anxiety-related behaviors is the family unit; in the case of rodents, this is the litter and the mother-young bond. ${ }^{25,74,75}$ Normally, investigators utilize individuals without consideration of the litter in which they were born. However, the litter is a structured unit involving the mother and her life history as well as the pups as they interact with one another and with the mother and research has demonstrated how much of adult behavior has its antecedents early in life.

A deciding factor in this environment is the sex ratio of the litter and, in the case of mice lacking functional copies of gene(s), the ratio of the various genotypes in the litter. Recent studies have deconstructed these two confounds and demonstrated that they have separate and distinct effects on the nature and quality of the individual's behavior later in adulthood, as well as on the metabolic activity in brain nuclei related to these behaviors. ${ }^{73,76,77}$ The finding that functional neural systems can be re-organized, depending upon the composition of the litter in which the individual develops, is startling. Yet it yields a deeper understanding of how neural systems are organized early in life.

Normally, litter composition reflects the sex ratio produced at birth, but there is evidence that prenatal environment (who your fetal neighbors are) and the postnatal period (the nature and quantity of maternal care) affect the adult behavioral phenotype. However, in none of these studies have these two periods been disassociated. Specifically, research demonstrating that the intrauterine sex ratio influences adult behavior failed to control for sex ratio of the litter postnatally. Similarly, research demonstrating that the sex ratio of the litter influences maternal behavior has not taken into account the prenatal sex ratio of the pregnant mother.

However, and contrary to the literature, deconstructing these sequential experiences reveals that it is the sex ratio of the litter postnatally that affects sexuality in adult males, not intrauterine position or maternal behavior. ${ }^{73,78}$ After controlling for prenatal sex ratio, we find that males raised in female-biased litters exhibit less mounting compared to males raised in litters of equal sex ratio or in male-biased litters. Further, males from female-biased litters are less attractive to sexually receptive females. These differences are not erased by sexual experience, suggesting that the effects of the sibling environment are permanent. Surprisingly, these males compensate for their lower attractiveness by being more efficient copulators.

In genetically-modified mice, not only is the sex ratio of the litter an issue but the ratio of the various genotypes is an equally important variable, particularly in model systems that are the result of the mating of Heterozygotes (HTZ) to yield litters of varying numbers of Wildtype (WT), HTZ, and Knockout (KO) young of both sexes. Typically, researchers using $\mathrm{KO}$ mice do not control for the early social environment of their experimental animals. This is a mistake since this early social environment has a powerful effect on shaping the adult behavioral phenotype and brain. A common mouse model is the Estrogen Receptor $\alpha$ (ERa) knockout that lacks a functional copy of this important sex steroid receptor. Not only has research revealed the role of this gene in differentiation of morphology and physiology but distinct behavioral phenotypes have also been characterized. The question is, to what extent are the behavioral phenotypes due to the absence of the gene or to the litter in which the individual develops.

Not only is it possible to distinguish males and females on the day of birth but it is also possible to genotype each individual in the litter using PCR to distinguish WT, HTZ, and KO individuals. Using this approach litters were reconstituted to control for sex ratio and genotype ratio. ${ }^{76,77}$ Results indicate that sex and genotype of siblings in the litter affected aggressive behaviors as well as patterns of metabolic 
activity in limbic nuclei in the social behavior network later in adulthood. Moreover, this pattern in males varied depending upon the genotype of their brothers and sisters. Principal components analysis revealed two components comprised of several amygdala and hypothalamic nuclei; the Ventromedial Hypothalamic nucleus (VMH) showed strong correlations in both clusters, suggesting its pivotal nature in the organization of the two neural networks. For example, WT females spend significantly more time in social contact in a Resident-Intruder test compared to KO females raised in same-sex, same-genotype litters. Further, it appears that female WT siblings are able to compensate for this deficit, just as $\mathrm{KO}$ siblings cause a deficit in WT females.

Cytochrome Oxidase ( $\mathrm{CO}$ ) histochemistry is a particularly useful tool for studies of the long-term effects of significant life history events. The abundance and activity of $\mathrm{CO}$ in a brain area is a measure of the metabolic capacity of that brain region. In other words, the $\mathrm{CO}$ abundance not only reflects the metabolic history of an area but, because it determines the amount of ATP available in a neuron, constrains the amount of activity a neuron can sustain..$^{79}$ Using this tool, we find that the neural networks that subserve sociosexual behavior vary in different ways. First, there is a significant genotype difference in the neural network of WT and KO mice and the compensation/deficit in the behavior are reflected in the metabolic activity of the neural circuit. The relative effects of sex, independent of genotype, and of genotype, independent of sex, are striking. Taken together, these findings indicate that in studies with genetically modified mice, the litter composition during the pre-weaning period must be considered as it can effect the development of behavior and the neural network responsible for the regulation of emotional behaviors.

\section{TRANSGENERATIONAL EPIGENETIC PROGRAMMING OF THE BRAIN TRANSCRIPTOME AND ANXIETY BEHAVIOR}

Michael Skinner and colleagues have developed a rat model in which the male germline bears a permanent epigenetic imprint, thereby creating an epigenetic transgenerational phenotype that is not
Context-dependent. ${ }^{80-83}$ This demonstrates that exposing gestating female rats to Vinclozolin during the period of sex determination induces an epigenetic transgenerational phenotype through reprogramming the germline in a sex-specific manner. Specifically, in each generation males whose ancestor had been treated showed accelerated onset of adult diseases such as cancer, prostate disease, kidney disease, and immune defects. The appearance of a series of new imprinted-like genes that transgenerationally transmits this altered epigenome to promote disease phenotypes appear not only in the sperm epigenome but also in the brain epigenome. ${ }^{82,83}$ Recently, a GermlineDependent epigenetic modification effect on mate preference has been demonstrated. ${ }^{84}$

The transcriptomes of the whole brain, amygdala, and hippocampus of these same F3 generation Vinclozolin-lineage and Control-lineage males show the same trends in expression with the COMT microarray results, demonstrating a decrease in all the vinclozolin gene sets in both the amygdala and hippocampus, but to a lesser extent in the latter. ${ }^{85}$ Hundreds of genes have altered expression in a transgenerational manner. Of these, a limited number show similar changes in the whole brain, amygdala, and hippocampus. Genes common to all three include Senp5 (SUMO/sentrin specific protease 5), Nfix (Nuclear factor I/X), Akap5 [A kinase (PRKA) anchor protein 5], NTrkb (Neurotrophic Tyrosine kinase receptor) and COMT, the latter three genes having been implicated in the etiology of schizophrenia and other affective disorders including autism and depression. ${ }^{62,86-89}$ Camk2a (calcium/calmodulin-dependent protein kinase II alpha subunit) was also regulated in the amygdala and hippocampus, this being a gene implicated effect in both learning and memory and stress-induced anxiety behavior..$^{90,91}$

Vinclozolin-lineage males spent more time in the light compartment and had more transitions than did control males. In the Elevated Plus maze, there was no difference between the lineages in \% open arm time and entries, but with significantly greater total arm entries for the Vinclozolin-lineage males ${ }^{85}$ Taken together, these studies indicate that the epigenetic transgenerational phenotype has a permanent alteration in the brain transcriptome in a manner that can 
influence behavior and genes implicated in anxietyrelated disorders, learning, and memory.

Surveying the recent literature for genes implicated in mental disorders reported by multiple laboratories and comparing it with our brain transcriptome analysis reveals that in the whole brain AUTS1 (candidate gene in region of chromosome 7 known as autism susceptibility locus 1) and Grik2 (Glutamate receptor, AMPA1) are decreased, while SLC6A4 (Serotonin transporter gene), Gria1 (Glutamate receptor, kainite 2), and S100 (calcium binding protein A4) are increased; the latter gene also shows a specific increase in the amygdala. Interestingly, AUTS2 (autism susceptibility locus 2 or engrailed homolog- EN2- in the rat) is not affected. ${ }^{24,92-95}$ (AUTS1 remains a strong candidate gene involved in autism, but AUTS2 is no longer considered to be so. ${ }^{95}$ ) Thus, it is significant that the AUTS1 and AUTS2 candidate genes map to the chromosome 7q location, the same region as Candidate gene 23 described by Chang et al; further, AUTS1 is reduced by the Vinclozolin-lineage males, but not AUTS2. ${ }^{83}$ The amygdala also showed an increase in expression in BDNF, DRD2, and S100. The increases in BDNF and DRD2 in amygdala are significant as the former has been implicated in Alzheimer's disease, affective disorders, posttraumatic stress disorder, schizophrenia, and substance dependence, while the latter has been implicated in PTSD, anxiety, social dysfunction, and depression. ${ }^{54,96}$

It is potentially instructive that a number of genes in the same literature were not found to be different in the Vinclozolin imprinted rat. For example, the gene RELN is downregulated in the schizophrenic brain and it has been suggested that this is due to hypermethylation of the RELN promoter. ${ }^{97,98}$ There is no evidence that the Vinclozolin-lineage male brain is different from the control-lineage male brain in this regard. The stability of these genes in face of epigenetic imprinting will enable them to be used as benchmarks for the effects of stress. Finally, other genes that have been implicated in autism and related affective disorders such as MECP2, GAD67, and IMMP2L (= IMP2) are not on the Affymetrix chip RAT230-2.0 used and so could not be evaluated. At this point there does not appear to be a rat homolog for NLGN4. ${ }^{99}$

\section{CONCLUSIONS}

The way the genetic background modifies responses to experiences throughout the life cycle can ultimately determine an individual's susceptibility to developing affective disorders. Recently, it has been discovered that early experiences can modify regulatory factors affecting gene expression in such a way that the DNA sequence itself is not changed but for generations afterwards an individual's physiology and behavior are substantially influenced. How this epigenetic modification can modulate the interaction of the environment and genetic constitution at the level of the brain, ultimately influencing agonistic and anxiety behaviors, is the next frontier.

\section{BIBLIOGRAPHY}

1. Kaminsky Z, Wang SC, Petronis A, 2006 Complex disease, gender and epigenetics. Ann Med 38: 530-544.

2. Ptak C, Petronis A, 2008 Epigenetics and complex disease: From etiology to new therapeutics. Ann Rev Pharmacol Toxicol 48: 257-276.

3. Yaeger D, Smith HG, Altshuler LL, 2006 atypical antipsychotics in the treatment of schizophrenia during pregnancy and the postpartum. Am J Psychiatry 163: 2064-2070.

4. Hines M, Brook C, Conway GS, 2004 Androgen and psychosexual development: core gender identity, sexual orientation and recalled childhood gender role behavior in women and men with congenital adrenal hyperplasia CAH. J Sex Res 41: 75-81.

5. Mill J, Petronis A, 2008 Pre- and peri-natal environmental risks for attention-deficit hyperactivity disorder ADHD: The potential role of epigenetic processes in mediating susceptibility. J Child Psychol Psychiatry 49: 1020-1030.

6. Resnick SM, Gottesman II, McGue M, 1993 Sensation seeking in opposite-sex twins: an effect of prenatal hormones? Behav Genet 23: 323-329.

7. Cohen-Bendahan CC, Buitelaar JK, van Goozen SH, Cohen-Kettenis PT, 2004 Prenatal exposure to testosterone and functional cerebral lateralization: A study in samesex and opposite-sex twin girls. Psychoneuroendocrinol 29: 911-916.

8. Cohen-Bendahan CC, Buitelaar JK, van Goozen SH, Orlebeke JF, Cohen-Kettenis PT, 2005 Is there an effect of prenatal testosterone on aggression and other behavioral traits? A study comparing same-sex and opposite-sex twin girls. Horm Behav 47: 230-237.

9. Fried-Cassoria M, Scholl TO, Borow LD, Strassman HD, Bowers EJ 1987 Depression and diethylstilbestrol exposure in women. J Reprod Med 32: 847-850. 
10. Pillard RC, Rosen LR, Meyer-Bahlburg H, et al, 1993 Psychopathology and social functioning in men prenatally exposed to diethylstilbestrol DES. Psychosom Med 55: 485-491.

11. Vessey MP, Fairweather DV, Norman-Smith B, Buckley J, 1983 A randomized double-blind controlled trial of the value of stilboestrol therapy in pregnancy: Long-term follow-up of mothers and their offspring. Br J Obstet Gynaecol 90: 1007-1017.

12. Landrigan PJ, Kimmel CA, Correa A, Eskanzai B, 2004 Children's health and the environment: Public health issues and challenges for risk assessment. Environ Health Perspect 112: 257-265.

13. Bateson P, Barker D, Clutton-Brock T, et al, 2004 Developmental plasticity and human health. Nature 430: 419-421.

14. Barker DJ, 2003 The developmental origins of adult disease. Eur J Epidemiol 18: 733-736.

15. Gluckman PD, Hanson MA, 2005 The Fetal Matrix: Evolution Development and Disease. Cambridge University Press, Cambridge.

16. Perisco AM, Bourgeron T, 2006 Searching for ways out of the autism maze: genetic epigenetic and environmental clues. Trends Neurosci 29: 349-358.

17. Tsankova N, Renthal W, Kumar A, Nestler EJ, 2007 Epigenetic regulation in psychiatric disorders. Nat Rev Neurosci 8: 355-367.

18. Crews D, 2008 Epigenetics and its implications for behavioral neuroendocrinology. Front Neuroendocrinol 29: 344-357.

19. Jirtle RL, Skinner MK, 2007 Environmental epigenomics and disease susceptibility. Nature Rev Genetics 8: 253-262.

20. Waterland RA, Lin JR, Smith CA, Jirtle JG, 2006 Post-weaning diet affects genomic imprinting at the insulin-like growth factor $2(\lg 2)$ locus. Hum Mol Genet 15: 705-716.

21. Dolinoy DC, Weidman JR, Jirtle RL, 2007 Epigenetic gene regulation: Linking early developmental environment to adult disease. Reprod Toxicol 23: 297-307.

22. Waterland RA, Dolinoy DC, Lin JR, Smith CA, Shi X, Tahiliani KG, 2006 Maternal methyl supplements increase offspring DNA methylation at Axin Fused. Genesis 44: 401-406.

23. Weaver IC, Champagne FA, Brown SE, et al, 2005 Reversal of maternal programming of stress responses in adult offspring through methyl supplementation: Altering epigenetic marking later in life. J Neurosci 25: 11045-11054.

24. Weaver IC, Meaney JJ, Szyf M, 2006 Maternal care effects on the hippocampal transcriptome and anxietymediated behaviors in the offspring that are reversible in adulthood. Proc Nat Acad Sci USA 103: 3480-3484.

25. Meaney MJ, 2001 Maternal care gene expression and the transmission of individual differences in stress reactivity across generations. Ann Rev Neurosci 24: 161-192.
26. Meaney MJ, Syzf M, 2005 Environmental programming of stress responses through DNA methylation: life at the interface between a dynamic environment and a fixed genome. Dialogues Clin Neurosci 7: 103-123.

27. Caspi A, McClay J, Moffitt TE, et al, 2002 Role of genotype in the cycle of violence in maltreated children. Science 297: 851-854.

28. Caspi A, Sugden K, Moffitt TE, et al, 2003 Influence of life stress on depression: moderation by a polymorphism in the 5-HTT gene. Science 301: 386-389.

29. Davies W, Lynn PM, Y Relkovic D, Wilkinson LS, 2008 Imprinted genes and neuroendocrine function. Front Neuroendocrinol 29: 413-427.

30. Keverne EB, Curley JP, 2008 Epigenetics brain evolution and behaviour. Front Neuroendocrinol 29: 398-412.

31. Crews D, McLachlan JA, 2006 Epigenetics evolution endocrine disruption health and disease. Endocrinology 147:Suppl: 4-10.

32. Woolf CM, 1997 Does the genotype for schizophrenia often remain unexpressed because of canalization and stochastic events during development? Psychol Med 27: 659-668.

33. Grossman AW, Churchill JD, McKinney BC, Kodish IM, Otte SL, Greenough WT, 2003 Experience effects on brain development: Possible contributions to psychopathology. J Child Psych 44: 33-63.

34. Cohen-Bendahan CC, van de Beek C, Berenbaum SA, 2005 Prenatal sex hormone effects on child and adult sex-typed behavior: Methods and findings. Neurosci Biobehav Rev 29: 353-384.

35. McEwen BS, 2004 Protection and damage from acute and chronic stress: Allostasis and allostatic overload and relevance to the pathophysiology of psychiatric disorders. Ann N Y Acad Sci 1032: 1-7.

36. McEwen BS, 2005 Glucocorticoids depression and mood disorders: Structural remodeling in the brain. Metab Clin Exper 54: Suppl 3: 20-23.

37. Sapolsky R, 2005 The influence of social hierarchy on primate health. Science 308: 648-652.

38. Magarinos AM, Verdugo JM, McEwen BS, 1997 Chronic stress alters synaptic terminal structure in hippocampus. Proc Natl Acad Sci 94: 14002-14008.

39. Mitra R, Jadhav S, McEwen BS, Vyas A, Chattarji S, 2005 Stress duration modulates the spatiotemporal patterns of spine formation in the basolateral amygdala. Proc Natl Acad Sci 102: 9371-9376.

40. Vyas A, Mitra R, Shakaranarayana R, McEwen BS, Chattarji S, 2002 Chronic stress induces contrasting patterns of dendritic remodeling in hippocampal and amygdaloid neurons. J Neurosci 22: 6810-6818.

41. Wellman CL, 2001 Dendritic reorganization in pyramidal neurons in medial prefrontal cortex after chronic corticosterone administration. J Neurobiol 49: 245-253.

42. Liston C, Miller MM, Goldwater DS, et al, 2006 Stressinduced alterations in prefrontal cortical dendritic morphology predict selective impairments in perceptual 
attentional set-shifting. J Neuroscience 26: 7870-7874.

43. Czéh B, Müller-Keuker JI, Rygula R, et al, 2007 Chronic social stress inhibits cell proliferation in the adult medial prefrontal cortex: Hemispheric asymmetry and reversal by fluoxetine treatment. Neuropsychopharmacol 32: 1490-1503.

44. Pham K, Nacher J, Hoff PR, McEwen BS, 2003 Repeated restraint stress suppresses neurogenesis and induces biphasic PSA-NCAM expression in the adult rat dentate gyrus. Eur J Neurosci 17: 879-886.

45. Sandi C, Merino JJ, Cordero MI, Touyarot K, Venero C, 2001 Effects of chronic stress on contextual fear conditioning and the hippocampal expression of the neural cell adhesion molecule its polysialylation and L1. Neuroscience 102: 329-339.

46. Wood GE, Young LT, Reagan LP, McEwen BS, 2005 Acute and chronic restraint stress alter the incidence of social conflict in male rats. Horm Behav 43: 205-213.

47. Luine V, Beck K, Frankfurt M, MacLusky N, 2007 Chronic stress and neural function: Accounting for and age J Neuroendocr 19: 743-751.

48. Isgor C, Kabbaj M, Akil H, Watson SJ, 2004 Delayed effects of chronic variable stress during peripubertaljuvenile period on hippocampal morphology and on cognitive and stress axis functions in rats. Hippocampus 14: 693-648.

49. Westenbroek C, Den Boer JA, Veenhuis M, Ter Horst CJ, 2004 Chronic stress and social housing differentially affect neurogenesis in male and female rats. Brain Res Bull 64: 303-308.

50. Yehuda R, Engel SM, Brand SR, Seckl J, Marcus SM, Berkowitz GS, 2005 Transgenerational effects of posttraumatic stress disorder in babies of mothers exposed to the World Trade Center attacks during pregnancy. J Clin Endocrinol Metab 90: 4115-4118.

51. Mill J, Tang T, Kaminsky Z, et al, 2008 Epigenomic profiling reveals DNA-methylation changes associated with major psychoses. Am J Hum Genet 82: 696-711.

52. Cook JD, Davis BJ, Cai S-L, Barrett JC, Conti CJ, Walker CL, 2005 Interaction between genetic susceptibility and early-life environmental exposure determines tumorsuppressor-gene penetrance. Proc Nat Acad Sci USA 102: 8644-8649.

53. Thomassin H, Flavin M, Espinás M, Grange T, 2001 Glucocorticoid- induced DNA demethylation and gene memory during development. FREE EMBO J 20: 19741983.

54. Lawford BR, Young R, Noble EP, Kann B, Ritchie T, 2006 The D2 dopamine receptor DRD2 gene is associated with co-morbid depression anxiety and social dysfunction in untreated veterans with post-traumatic stress disorder. Eur Psychiatry 21: 180-185.

55. Popendikyte V, Laurinavicius A, Paterson AD, Macciardi F, Kennedy JL, Petronis A, 1999 DNA methylation at the putative promoter region of the human dopamine D2 receptor gene. NeuroReport 10 1249-1255
56. Petronis A, Gottesman II, Kan P, et al, 2003 Monozygotic twins exhibit numerous epigenetic differences: Clues to twin discordance? Schizophr Bull 29: 169-178.

57. Lee E-S, Chena H, Shepherd KR, Lamango NS, Soliman KFA, Charlton CG, 2004 The inhibitory role of methylation on the binding characteristics of dopamine receptors and transporter. Neurosci Res 48: 335-344.

58. Li J, Guo Y, Schroeder FA, et al, 2004 Dopamine D2-like antagonists induce chromatin remodeling in striatal neurons through cyclic AMP-protein kinase A and NMDA receptor signaling. J Neurochem 90: 1117-1131.

59. Gross C, Hen R, 2004 The developmental origins of anxiety. Nature Rev Neurosci 5: 545-552.

60. Fraga MF, Ballestar E, Paz MF, et al, 2005 Epigenetic differences arise during the lifetime of monozygotic twins. Proc Natl Acad Sci 102: 10604-10609.

61. Petronis A, 2006 Epigenetics and twins: Three variations on the theme. Trends Genet 22: 347-350.

62. O'Donovan MC, Williams NM, Owen MJ, 2003 Recent advances in the genetics of schizophrenia. Hum Mol Genet 12: R125-R133.

63. Mill J, Dempster E, Caspi A, Williams B, Moffitt T, Craig I, 2006 Evidence for monozygotic twin MZ discordance in methylation level at two CpG sites in the promoter region of the catechol-o-methyltransferase COMT gene. Am J Med Genet Part B 141B: 421-425.

64. Hull EM, Meisel RL, Sachs BD 2002 Male sexual behavior. In: Pfaff DW, Arnold AP, Etgen AM, Fahrbach SE, Rubin RT (eds) Hormones Brain and Behavior Volume One. Academic Press New York; pp, 1-138.

65. Blaustein JD, Erskine MS 2002 Feminine sexual behavior: Cellular integration of hormonal and afferent information in the rodent brain. In: Pfaff DW, Arnold AP, Etgen AM, Fahrbach SE, Rubin RT (eds) Hormones Brain and Behavior Volume One. Academic Press New York; pp, 139-214.

66. DeVries GJ, Simerly RB 2002 Anatomy development function of sexually dimorphic neural circuits in the mammalian brain. In: Pfaff DW, Arnold AP, Etgen AM, Fahrbach SE, Rubin RT (eds) Hormones Brain and Behavior Volume Four. Academic Press New York; pp, 137-192.

67. Fleming AS, O’Day D, Kraemer G, 1999 Neurobiology of mother-infant interactions: Experience and central nervous system plasticity across development. Neurosci Biobehav Rev 23: 673-685.

68. Febo M, Numan M, Ferris CF, 2005 Functional magnetic resonance imaging shows oxytocin activates brain regions associated with mother-pup bonding during suckling. J Neurosci 25: 11637-11644.

69. Numan MJ, Insel TR 2003 The Neurobiology of Parental Behavior. Springer, New York.

70. Gonzalez-Mariscal G, Poindron P 2002 Parental care in mammals: Immediate internal and sensory factors of control In: Pfaff DW, Arnold AP, Etgen AM, Fahrbach SE, Rubin RT (eds) Hormones Brain and Behavior 
Volume One. Academic Press New York; pp, 215-298.

71. Simon NG 2002 Hormonal processes in the development and expression of aggressive behavior. In: Pfaff DW, Arnold AP, Etgen AM, Fahrbach SE, Rubin RT (eds) Hormones Brain and Behavior Volume One. Academic Press New York; pp, 339-392.

72. Newman SW, 1999 The medial extended amygdala in male reproductive behavior: A node in the mammalian social behavior network. Ann N Y Acad Sci 877: 242257.

73. Crews D, Lou W, Fleming A, Ogawa S, 2006 From gene networks underlying sex determination and gonadal differentiation to the development of neural networks regulating sociosexual behavior. Brain Res 1126: 109121.

74. Fleming AS, Kraemer GW, Gonzalez A, Lovic V, Rees S, Melo A, 2002 Mothering begets mothering: The transmission of behavior and its neurobiology across generations. Physiol Pharm Behav 73: 61-75.

75. Moore CL 1995 Maternal contributions to mammalian reproductive development and divergence of males and females. In: Slater PJP, Rosenblatt JS, Snowdon CT, Milinski M (eds) Advances in the Study of Behavior, Academic Press, New York; pp, 47-118.

76. Crews D, Fuller T, Mirasol EG, Pfaff DW, Ogawa S, 2004 Postnatal environment affects behavior of adult transgenic mice. Exp Biol Med 229: 935-939.

77. Crews D, Rushworth D, Gonzalez-Lima F, Ogawa S, 2009 Litter environment affects agonistic behavior and brain metabolic activity of adult estrogen receptor a knockout mice. Front Behav Neurosci 3: 12. doi:10.3389/ neuro.08.012.200.

78. deMedeiros CBL, Rees SL, Llianas M, Fleming A, Crews D, 2009 Effects of prenatal and postnatal litter sex composition on adult sexual behavior of male rats. Submitted to Hormones and Behavior.

79. Sakata JT, Crews D, Gonzalez-Lima F, 2005 Behavioral correlates of differences in neural metabolic activity. Brain Res Rev 48: 1-15.

80. Anway MD, Cupp AS, Uzumcu M, Skinner MK, 2005 Epigenetic transgenerational actions of endocrine disruptors and male fertility. Science 308: 1466-1469.

81. Anway MD, Skinner MK, 2006 Epigenetic transgenerational actions of endocrine disruptors. Endocrinology 147:Suppl: 43-49.

82. Anway MD, Leathers C, Skinner MK, 2006 Endocrine disruptor vinclozolin induced epigenetic transgenerational adult onset disease. Endocrinology 147: 5515-5523.

83. Guerrero-Bosagna CM, Skinner MK, 2009 Epigenetic transgenerational effects of endocrine disruptors on male reproduction. Semin Reprod Med 27: 403-408.

84. Crews D, Gore AC, Hsu TS, et al, 2007 Transgenerational epigenetic imprints and mate preference. Proc Nat Acad Sci USA 104: 5942-5946.

85. Skinner MK, Anway MD, Savenkova MI, Gore AC,
Crews D, 2008 Transgenerational epigenetic programming of the brain transcriptome and anxiety behavior. PLoS One 3 (E3745) 1-11.

86. Wilson GM, Flibotte S, Chopra V, Melnyk BL, Honer WG, Holt RA, 2006 DNA copy-number analysis in bipolar disorder and schizophrenia reveals aberrations in genes involved in glutamate signaling. Hum Mol Genet 15: 743-749.

87. Pezet S, Malcangio M, 2004 Brain-derived neurotrophic factor as a drug target for CNS disorders. Expert Opin Ther Targets 8: 391-399.

88. Tsai SJ, 2004 Down-regulation of the Trk-B signal pathway: the possible pathogenesis of major depression. Med Hypotheses 62: 215-218.

89. Tsai SJ, 2006 TrkB partial agonists: Potential treatment strategy for epilepsy mania and autism. Med Hypotheses 66: 173-175.

90. Wang H, Ferguson GD, Pineda VV, Cundiff PE, Storm DR, 2004 Overexpression of type-1 adenylyl cyclase in mouse forebrain enhances recognition memory and LTP. Nature Neurosci 7: 635-642.

91. Muller MB, Zimmermann S, Sillaber I, et al, 2003 Limbic corticotropin-releasing hormone receptor 1 mediates anxiety-related behavior and hormonal adaptation to stress. Nature Neurosci 6: 1100-1107.

92. International Molecular Genetic Study of Autism Consortium (IMGSAC) 2001 Further characterization of the autism susceptibility locus AUTS1 on chromosome 7q. Human Mol Genetics 10: 973-982.

93. Muhle R, Trentacoste SV, Rapin I, 2004 The genetics of autism. Pediatrics 113: 472-486.

94. Cantor RM, Kono N, Duvall JA, et al, 2005 Replication of autism linkage: Fine mapping peak at 17q21. Amer J Hum Genet 76: 1050-1056.

95. Sultana R, Yu CE, Yu J, et al, 2002 Identification of a novel gene on chromosome 7q11 2 interrupted by a translocation breakpoint in a pair of autistic twins. Genomics 80: 129-134.

96. Zhang H, Ozbay F, Lappalainen J, et al, 2006 Brain derived neurotrophic factor BDNF gene variants and Alzheimer's disease affective disorders posttraumatic stress disorder schizophrenia and substance dependence. Am J Med Genet Part B 141B: 387-393.

97. Costa E, Chen Y, Davis J, et al, 2002 REELIN and schizophrenia: A disease at the interface of the genome and the epigenome. Mol Intervent 2: 47-57.

98. Dong E, Agis-Balboa RC, Simonini MV, Grayson DR, Costa E, Guidotti A, 2005 Reelin and glutamic acid decarboxylase 67 promoter remodeling in an epigenetic methionine-induced mouse model of schizophrenia. Proc Natl Acad Sci 102: 12578-12583.

99. Jamain S, Quach H, Betancur C, et al, 2003 Mutations of the X-linked genes encoding neuroligins NLGN3 and NLGN4 are associated with autism. Nature Genet 34: 27-29. 